\title{
After Over a Year of Pandemic: Mental Well-being and Life Satisfaction of Filipino College Students
}

\author{
Renante Adrogado Egcas ${ }^{1}$, Ryan Michael Flores Oducado ${ }^{2 *}$, Jerome Visperas \\ Cleofas $^{3}$, Judith Solasco Rabacal ${ }^{1}$ and Samson Mahidlawon Lausa ${ }^{1}$ \\ ${ }^{1}$ Graduate School, Northern Negros State College of Science \& Technology, Negros Occidental 6122, Philippines \\ ${ }^{2}$ College of Nursing, West Visayas State University, Iloilo 5000, Philippines \\ ${ }^{3}$ Department of Sociology and Behavioral Sciences, De La Salle University, Manila 1004, Philippines
}

\begin{abstract}
The COVID-19 pandemic has been there for over a year and may substantially negatively impact student's mental well-being. This study aimed to assess the subjective mental wellbeing and satisfaction with life of Filipino college students. This cross-sectional study involved the analysis of 1,141 college students in the Philippines. The data were collected using the Short Warwick-Edinburgh Mental Wellbeing Scale and the Satisfaction with Life Scale. Results indicated that while $52.8 \%$ reported high satisfaction with life, $40.2 \%$ had poor mental well-being. Self-reported health status $(\beta=1.899, p=.000)$, age $(\beta=0.179, p=.000)$, and year level $(\beta=0.306, p=.000)$ predicted mental well-being. On the other hand, subjective mental well-being $(\beta=0.736, p=.000)$, self-reported health status $(\beta=0.967, p=.000)$, and age $(\beta=0.691, p=.025)$ predicted life satisfaction. The COVID-19 pandemic has likely affected students' mental health and well-being. Interventions should be initiated to address the mental health needs of the students during this pandemic and even beyond the health crisis.
\end{abstract}

Keywords: COVID-19 pandemic, life satisfaction, mental health, Philippines, students

\begin{tabular}{l}
\hline \\
ARTICLE INFO \\
Article history: \\
Received: 27 July 2021 \\
Accepted: 24 September 2021 \\
Published: 03 December 2021 \\
DOI: https://doi.org/10.47836/pjssh.29.4.17 \\
E-mail addresses: \\
president@nonescost.edu.ph (Renante Adrogado Egcas) \\
rmoducado@wvsu.edu.ph (Ryan Michael Flores Oducado) \\
jerome.cleofas@dlsu.edu.ph (Jerome Visperas Cleofas) \\
judithrabacal.jr@gmail.com (Judith Solasco Rabacal) \\
smlausa@nonescost.edu.ph (Samson Mahidlawon Lausa) \\
* Corresponding author
\end{tabular}

\section{INTRODUCTION}

The rise of mental and psychological health problems is an area of concern arising during pandemics. Soon after COVID-19 was declared a pandemic in March 2020 (Cucinotta \& Vanelli, 2020), authorities and scholars have warned about the possible impact of the public health crisis on mental health and the rise of mental health issues (United Nations, 2020). The result of studies 
on the immediate impact of the COVID-19 outbreak on psychological well-being revealed poor and negative mental health outcomes (Kecojevic et al., 2020; Wang et al., 2020a, 2021b). Moreover, a crosscountry comparison disclosed that the Philippines were the two countries with the highest stress, anxiety, and depression (Wang et al., 2021a). Apart from the fear of getting infected by the virus are the new realities of home-schooling and significant changes to everyday lives as movements are restricted to reduce and contain viral transmission (Oducado \& Estoque, 2021; Rodríguez-Rey et al., 2020). Lockdown restrictions and social distancing measures hurt economic well-being, psychological health, and quality of life (Le et al., 2020; Ren et al., 2021; Tran et al., 2020). Despite the developments of vaccines to protect against the disease, the number of cases in some parts of the world and the Philippines continues to rise. As of July 7, 2021, there are $184,324,026$ confirmed cases and 3,992,680 deaths of COVID-19 worldwide (World Health Organization, 2021) and 1,450,110 infected and 25,459 deaths in the country (Philippine Department of Health, 2021).

Continuously monitoring the developments of the pandemic and its likely effect on mental health is necessary as the pandemic appears to remain for some time. A systematic review found that the COVID-19 pandemic negatively impacted the population's mental health (Xiong et al., 2020). In another study, younger groups and students' psychological health are more affected by the pandemic (Tee et al., 2020). The COVID-19 crisis is fuelling a mental health crisis as the pandemic wears on to upset the lives of young people across the globe (Dodson, 2020). Pre-pandemic statistics of the World Health Organization (2020) show that 16 percent of people aged 10 to 19 years old worldwide live with mental health conditions, and suicide is the fourth leading cause of death for 15 and 19 years old. A study involving 30 countries reported a 10.8 percent lifetime prevalence of depression (Lim et al., 2018). University students are particularly vulnerable as there is an increased likelihood of experiencing common psychological problems throughout adolescence and are peaking in early adulthood (HernándezTorrano et al., 2020). Unfortunately, many students never used mental health services despite having moderate or severe mental health symptoms during the pandemic (Lee et al., 2021).

As the global health crisis continues in the Philippines, Asia, and many parts of the world, experts anticipate a long-term impact of the pandemic on people's mental health (Joseph, 2021), and scholars speculate that a bigger wave of a mental health crisis can be expected in the aftermath of the pandemic (Rabacal et al., 2020; Repišti et al., 2020). While there had been many studies on the psychological impact of the pandemic on the population and students, most of the studies were done at the early onset of the pandemic (e.g., Kecojevic et al., 2020; Labrague et al., 2021; Superio et al., 2021; Tee et al., 2020). Moreover, previous 
studies commonly used various outcome variables for possible psychopathologies, such as stress, depression, and anxiety (e.g., Hamaideh et al., 2021; Le et al., 2020; Lee et al., 2021; Ren et al., 2021; Simegn et al., 2021; Wang et al., 2021a, 2021b), however, few looked into the subjective mental well-being and life satisfaction being arguably indicators or possible predictors of current or future mental health outcomes. Moreover, qualitative evidence suggests that due to quarantine restrictions and campus closures, Filipino college students have failed to experience developmental milestones such as in-person co-learning and recreational activities with peers, engagement in internships and practicums in their desired industries, and preparations to launch themselves into the productive workforce (Cleofas, 2020). These pandemic-induced life interruptions may lead to poorer well-being, quality of life, and sentiments about the future among these emerging adults.

Since the conduct of studies in the country and elsewhere found in the literature (e.g., Lee et al., 2021; Superio et al., 2021; Tee et al., 2020), the students may have been continually exposed to pandemic-induced stressors for more than a year. There is a need to revisit the mental health conditions of these students to determine whether current policies and interventions need to be adjusted to address their needs. Thus, this study aimed to examine the subjective mental well-being and satisfaction with life of Filipino college students.

\section{METHODS \\ Research Design, Sample, and Data Collection}

It was a cross-sectional study. The sample of this study consisted of college students in one government-funded college in the Western Visayas region of the Philippines. The sample size was computed using the Raosoft sample size calculator. A sample of 364 was required for a population of 6,893 with a confidence level of $95 \%$, a margin of error of $5 \%$, and a response distribution of $50 \%$. More than the required sample size for this study responded to the first wave of the web-based survey administered on July 1, 2021. However, we included only 1,141 responses in the analysis. In addition, we excluded five respondents who reported high-income status because of the very few numbers (less than 1 percent of the total sample) of respondents in the category. The study was conducted in accordance with the Declaration of Helsinki. Administrative clearance for the sound and ethical conduct of the study was obtained from the Public University where the study was conducted. The online survey (Google Forms) was posted in the school's official social media groups and chat groups. Students were asked to proceed with the survey only upon consenting to participate in the study.

\section{Instruments}

The Short Warwick-Edinburgh Mental Wellbeing Scale (SWEMWS) and the Satisfaction with Life Scale (SWLS) were the main research instruments utilized in the study. The SWEMWS of the NHS Health 
Scotland, University of Warwick, and University of Edinburgh (2008) consisted of seven items that measured subjective mental well-being in this study. The scores in the SWEMWBS were first summed up for each of the seven items (total score is from 7 to 35), using a 5-point scale that ranges from "1-None of the time" to "All of the time-5." After which, the transformation of the total raw scores into metric scores was done using a conversion table (StewartBrown et al., 2009). The scores were interpreted as 7 to 20 are low or poor (17 or less for probable depression, 18-20 for possible depression), 28 to 35 are high, and between 20 and 28 are average mental wellbeing (Trabelsi et al., 2021). The SWLS of Diener et al. (1985) measured global cognitive judgment of life satisfaction. The SWLS was scored by summing the scores for each of the five items, which are scored from "1-Strongly disagree" to "7-Strongly agree," and the total score is from five to 35 . Scores were interpreted as 5 to 14 are dissatisfied ( 5 to 9 for extremely dissatisfied, 10 to 14 for dissatisfied), 25 to 35 are highly satisfied ( 25 to 29 are satisfied, 30 to 35 are highly satisfied), and between 14 to 25 are moderate life satisfaction (15 to 19 are slightly below average in life satisfaction, 20 to 24 are average life satisfaction; Pavot \& Diener, 2013). While tool developers reported acceptable internal consistency of the SWEMWBS and SWLS, both scales had a Cronbach's alpha of .87 when used among Filipino samples (Cleofas \& Oducado, 2021). Self-reported health status was determined using a one-item scale with responses ranging from "Poor1" to "Excellent-5" (Haddock et al., 2006; Oducado et al., 2021). The respondents were also asked if they suffer from any chronic illness or comorbidities, answerable by "Yes-1, "No-2", and "Don't know-3." The socio-demographic information of the respondents was also collected in the first part of the survey.

\section{Statistical Data Analysis}

Data were analyzed using the IBM SPSS software version 23. For description purposes, frequency, percentage, standard deviation (SD), and mean were utilized. A one-way Analysis of Variance with Scheffe's procedure was used to compare means of more than two groups. In comparison, a t-test for independent samples was employed to compare the means of two independent groups. Correlates and predictors were identified using Pearson's $r$ and multiple linear regression analysis using the stepwise method. Alpha level of significance was set at .05 .

\section{RESULTS}

Table 1 presents the profile of 1,141 respondents. The average age and selfreported health of the respondents were $21.78+3.28$ and $4.06+.21$, respectively. The majority were females $(74.6 \%)$, single (96.7\%), junior level (37.7\%), low-income status $(67.7 \%)$, not working or full-time students $(77.9 \%)$, with residence located in the city (55.4\%), are living with their family (94.8\%), and do not have any chronic illness or comorbidities $(78.8 \%)$. 
Table 2 shows that $40.2 \%$ and $42.3 \%$ had poor and average subjective mental well-being, respectively. On the other hand, $52.8 \%$ were highly satisfied with life.

Table 3 shows the Pearson's r result revealing that age $(\mathrm{r}=.131, \mathrm{p}=.000)$ and self-reported health $(r=.267, p=.005)$ were

Table 1

Profile of college students

\begin{tabular}{|c|c|c|c|c|}
\hline Profile & Mean & $\mathrm{SD}$ & $\mathrm{f}$ & $\%$ \\
\hline Age & 21.78 & 3.28 & & \\
\hline $\begin{array}{l}\text { Self-reported health } \\
\text { status }\end{array}$ & 4.06 & 0.71 & & \\
\hline \multicolumn{5}{|l|}{ Sex } \\
\hline Male & & & 29 & 25.4 \\
\hline Female & & & 851 & 74.6 \\
\hline \multicolumn{5}{|l|}{ Marital status } \\
\hline Single & & & 1103 & 96.7 \\
\hline Married & & & 38 & 3.3 \\
\hline \multicolumn{5}{|l|}{ Family income status } \\
\hline Low income & & & 772 & 67.7 \\
\hline Middle income & & & 369 & 32.2 \\
\hline \multicolumn{5}{|l|}{ Work status } \\
\hline Yes & & & 252 & 22.1 \\
\hline No & & & 889 & 77.9 \\
\hline \multicolumn{5}{|l|}{ Location of residence } \\
\hline City & & & 632 & 55.4 \\
\hline Town & & & 509 & 44.6 \\
\hline \multicolumn{5}{|c|}{ Family living arrangement } \\
\hline Yes & & & 1082 & 94.8 \\
\hline No & & & 59 & 5.2 \\
\hline \multicolumn{5}{|l|}{ Year level } \\
\hline Freshman & & & 197 & 17.3 \\
\hline Sophomore & & & 331 & 29.0 \\
\hline Junior & & & 430 & 37.7 \\
\hline Senior & & & 183 & 16.1 \\
\hline \multicolumn{5}{|c|}{ Presence of chronic illness or comorbidities } \\
\hline Yes & & & 59 & 5.2 \\
\hline No & & & 899 & 78.8 \\
\hline Don't know & & & 183 & 16.0 \\
\hline
\end{tabular}

significantly related to mental well-being. Also, t-test for independent samples and one-way ANOVA revealed that mental well-being significantly differed according to marital status $(\mathrm{t}=-2.514, \mathrm{p}=.012)$, academic year level $(\mathrm{F}=4.053, \mathrm{p}=.007)$, and if the student suffers from chronic illness $(\mathrm{F}=9.508, \mathrm{p}=.000)$. Post hoc analysis revealed that the subjective mental wellbeing of juniors $(p=.020)$ and seniors $(p=.028)$ were significantly higher than that of freshmen college students. In addition, those who do not suffer from any chronic illness had significantly higher $(p=.000)$ mental well-being than those who do not know if they have chronic illness or comorbidities.

The Pearson's r result in Table 4 shows that mental well-being $(\mathrm{r}=.636, \mathrm{p}=.000)$, age $(r=.064, r=.030)$, and self-reported general health status $(\mathrm{r}=.271, \mathrm{p}=.000)$ were significantly correlated with life satisfaction. Additionally, the result of the t-test for independent samples and one-way ANOVA revealed that satisfaction with life significantly differed based on marital status

Table 2

Level of mental well-being and life satisfaction of college students

\begin{tabular}{lcc}
\hline $\begin{array}{l}\text { Level of mental well-being and } \\
\text { life satisfaction }\end{array}$ & f & $\%$ \\
\hline Mental well-being $(\mathrm{M}=23.16, \mathrm{SD}=5.10)$ & \\
$\quad$ High (28 to 35) & 199 & 17.4 \\
Average (21 to 27) & 483 & 42.3 \\
Low (7 to 20) & 459 & 40.2 \\
Life satisfaction $(\mathrm{M}=24.30, \mathrm{SD}=6.29)$ & \\
Highly satisfied (25 to 35) & 603 & 52.8 \\
Moderately satisfied (15 to 24) & 451 & 39.5 \\
Dissatisfied (5 to 14) & 87 & 7.6 \\
\hline
\end{tabular}


Table 3

Correlates of subjective mental well-being among college students

\begin{tabular}{|c|c|c|c|c|}
\hline Variables & M & $\mathrm{SD}$ & Test statistics & $p$-value \\
\hline $\mathrm{Age}^{\dagger}$ & & & $.131^{*}$ & .000 \\
\hline Self-reported health status ${ }^{\dagger}$ & & & $.267^{*}$ & .005 \\
\hline $\mathrm{Sex}^{\ddagger}$ & & & 0.709 & .479 \\
\hline Male & 23.35 & 5.33 & & \\
\hline Female & 23.10 & 5.01 & & \\
\hline Marital status & & & $-2.514^{*}$ & .012 \\
\hline Single & 23.09 & 5.11 & & \\
\hline Married & 25.06 & 4.54 & & \\
\hline Family income status ${ }^{\ddagger}$ & & & -0.521 & .602 \\
\hline Low income & 23.11 & 5.13 & & \\
\hline Middle income & 23.28 & 5.04 & & \\
\hline Work status ${ }^{\ddagger}$ & & & 1.816 & .070 \\
\hline Yes & 23.68 & 5.40 & & \\
\hline No & 23.02 & 5.00 & & \\
\hline Location of residence & & & 0.365 & .589 \\
\hline City & 23.09 & 5.03 & & \\
\hline Town & 23.26 & 5.18 & & \\
\hline Family living arrangement & & & 1.675 & .094 \\
\hline Yes & 23.22 & 5.12 & & \\
\hline No & 22.08 & 4.70 & & \\
\hline Year level ${ }^{\S}$ & & & $4.053^{*}$ & .007 \\
\hline Freshman & 22.11 & 4.88 & & \\
\hline Sophomore & 23.09 & 4.81 & & \\
\hline Junior & 23.48 & 5.38 & & \\
\hline Senior & 23.69 & 5.05 & & \\
\hline $\begin{array}{l}\text { Presence of chronic illness or } \\
\text { comorbidities }^{\S}\end{array}$ & & & $9.508^{*}$ & .000 \\
\hline Yes & 22.18 & 4.95 & & \\
\hline No & 23.50 & 5.13 & & \\
\hline Don't know & 21.85 & 4.74 & & \\
\hline
\end{tabular}

Note: ${ }^{\dagger}$ Pearson $\mathrm{r}$ correlation, ${ }^{\star} \mathrm{t}$-test for independent group, ${ }^{\S}$ Analysis of Variance ${ }^{*} \mathrm{p}<.05$

Table 4

Correlates of life satisfaction among college students

\begin{tabular}{lcccc}
\hline Variables & M & SD & Test statistics & $p$-value \\
\hline Mental well-being $^{\dagger}$ & & & $.626^{*}$ & .000 \\
Age $^{\dagger}$ & & & $.064^{*}$ & .030 \\
Self-reported health status $^{\dagger}$ & & & $.271^{*}$ & .000 \\
Sex $^{\ddagger} \quad$ & & 0.152 & .879 \\
$\quad$ Male & & & & \\
$\quad$ Female & 24.35 & 6.29 & & .000 \\
$\quad$ Marital status & 24.28 & 6.30 & & \\
$\quad$ Single & & & $-4.211^{*}$ & \\
\hline
\end{tabular}


Table 4 (continue)

\begin{tabular}{|c|c|c|c|c|}
\hline Variables & $\mathrm{M}$ & SD & Test statistics & $p$-value \\
\hline Married & 26.58 & 3.24 & & \\
\hline Family income status & & & $-2.260^{*}$ & .024 \\
\hline Low income & 24.01 & 6.43 & & \\
\hline Middle income & 24.91 & 5.97 & & \\
\hline Are you a working student & & & 0.674 & .500 \\
\hline Yes & 24.54 & 6.41 & & \\
\hline No & 24.23 & 6.26 & & \\
\hline Location of residence & & & 1.207 & .228 \\
\hline City & 24.50 & 6.06 & & \\
\hline Town & 24.05 & 6.57 & & \\
\hline Family living arrangement & & & $2.441^{*}$ & .015 \\
\hline Yes & 24.41 & 6.27 & & \\
\hline No & 22.36 & 6.45 & & \\
\hline Year level ${ }^{\S}$ & & & 1.481 & .218 \\
\hline Freshman & 23.49 & 6.14 & & \\
\hline Sophomore & 24.52 & 6.16 & & \\
\hline Junior & 24.33 & 6.61 & & \\
\hline Senior & 24.72 & 5.92 & & \\
\hline Presence of chronic illness or comorbidities ${ }^{\S}$ & & & $12.335^{*}$ & .000 \\
\hline Yes & 23.24 & 5.96 & & \\
\hline No & 24.77 & 6.20 & & \\
\hline Don't know & 22.25 & 6.47 & & \\
\hline
\end{tabular}

Note: ${ }^{\dagger}$ Pearson $\mathrm{r}$ correlation, ${ }^{\mathrm{t}} \mathrm{t}$-test for independent group, ${ }^{\S}$ Analysis of Variance ${ }^{*} \mathrm{p}<.05$

Table 5

Regression analysis of predictors of mental well-being among college students

\begin{tabular}{lcccc}
\hline Independent variables & $\beta$ & $\mathrm{t}$ & $p$-value & $95 \%$ CI for $\beta$ \\
\hline (Constant) & 10.771 & 8.45 & .000 & 8.27 to 13.28 \\
Self-reported health status & 1.899 & 9.32 & .000 & 1.50 to 2.30 \\
Age & 0.179 & 3.95 & .000 & 0.090 to 0.268 \\
Year level & 0.306 & 1.97 & .000 & 0.001 to 0.611 \\
\hline
\end{tabular}

Note. $\mathrm{R}=.301 ; \mathrm{R}^{2}=.091 ;$ Std. Error of the Estimate $=4.87 ; \mathrm{F}=37.87 ; \mathrm{p}=.000$

$(t=-4.211, p=.000)$, family income status $(\mathrm{t}=-2.260, \mathrm{p}=.024)$, those living with family $(t=2.441, p=.015)$, and presence or absence of any chronic illness or comorbidities $(\mathrm{F}=12.335, \mathrm{p}=.000)$. Post hoc analysis unveiled that those who do not suffer from chronic illness have significantly higher $(p=.000)$ life satisfaction compared to those who do not know if they have any chronic illness or comorbidities.

Presented in Table 5 are the predictors of mental well-being. Multiple linear regression analysis revealed that selfreported health status $(\beta=1.899, \mathrm{p}=.000)$, age $(\beta=0.179, p=.000)$, and year level $(\beta=0.306, p=.000)$ were significant 
Table 6

Regression analysis of predictors of life satisfaction

\begin{tabular}{lcccc}
\hline Independent variables & $\beta$ & $\mathrm{t}$ & $p$-value & $95 \%$ CI for $\beta$ \\
\hline (Constant) & 2.403 & 2.36 & .018 & 0.409 to 4.396 \\
Mental well-being & 0.736 & 25.17 & .000 & 0.679 to 0.794 \\
Self-reported health status & 0.967 & 4.58 & .000 & 0.553 to 1.381 \\
Age & 0.691 & 2.25 & .025 & 0.087 to 1.295 \\
\hline
\end{tabular}

Note. $\mathrm{R}=.638 ; \mathrm{R}^{2}=.407 ;$ Std. error of the estimate $=4.85 ; \mathrm{F}=259.76 ; \mathrm{p}=.000$

predictors of mental well-being. In addition, the regression model explained $9.1 \%$ of the variances of subjective mental well-being $(\mathrm{F}=37.87, \mathrm{p}=.000)$.

The regression model (Table 6) explained $40.7 \%$ of the variances of the satisfaction with life $(\mathrm{F}=259.76, \mathrm{p}=.000)$. Subjective mental well-being $(\beta=0.736, p=.000)$, selfreported health status $(\beta=0.967, \mathrm{p}=.000)$, and age $(\beta=0.691, p=.025)$ were significant predictors of life satisfaction.

\section{DISCUSSION}

This study investigated college students' mental well-being and satisfaction after over a year of the pandemic health crisis. After almost sixteen months since the COVID-19 pandemic began, we found a relatively significant number of college students reporting poor mental well-being suggesting possible or probable psychopathology. A systematic review of the effects of COVID-19 on psychological outcomes found that the COVID-19 pandemic negatively impacted people's mental health (Xiong et al., 2020). Studies conducted during the lockdown period and early parts of the pandemic in the Philippines have shown that college students experience fear (Superio et al., 2021), anxiety (Cleofas \&
Rocha, 2021), lockdown fatigue (Labrague et al., 2021), loneliness (Labrague \& Ballad, 2020), and were moderately or severely affected by the pandemic (Tee et al., 2020). Nevertheless, the literature and our findings suggest that the COVID-19 pandemic continues to have an undesirable impact on students' mental health. The proportion of students having poor mental well-being in our study after more than a year of the pandemic is disturbing and is an area of concern. Poor psychological or mental wellbeing is linked with depression, stress, and anxiety (Malone \& Wachholtz, 2018; Ceri \& Cicek, 2021; Wąsowicz et al., 2021). Additionally, our result also has important implications for the early implementation of suicide prevention strategies. Depression or poor mental health is a risk factor for suicidal behaviors before and during the pandemic (Brådvik, 2018; Elbogen et al., 2021). Although a longitudinal survey found no significant changes in the respondents' stress, anxiety, and depression levels during the initial phase and four weeks later of the COVID-19 outbreak (Wang et al., 2020b), there is also evidence showing that suicidal ideation was found to increase over time since the start of the COVID-19 pandemic (Mamun, 2021). 
A pre-pandemic meta-analysis also revealed a higher prevalence of self-harm, non-suicidal self-injury, and suicidal behaviors among children and adolescents in low and middle-income, non-Western countries (Lim et al., 2019). And while the central focus of public health initiatives during outbreaks usually revolves around the physical and biological effects of the epidemic, the increasing mental health burden calls for enhanced mental health support (Ho et al., 2020a). Well-being initiatives and other positive psychological measures such as Cognitive Behavioral Therapy (Soh et al., 2020; Zhang \& Ho, 2017) may be undertaken to address the potentially growing number of psychological problems during the global health crisis. Nevertheless, it may also be valuable not only to attribute students' poor mental wellbeing to the effect of the pandemic. Issues in mental and psychological health may also be due to other factors like the altered learning landscape and academic difficulties (Burns et al., 2020; Oducado \& Estoque, 2021).

Also, in this study, higher self-reported health predicts higher mental well-being and greater life satisfaction. Although it is not a significant predictor, students without chronic disease or comorbidities have higher well-being and life satisfaction scores in the bivariate analysis. Correspondingly, perception of good health status is associated with lower levels of stress, anxiety, depression, and the psychological impact of the pandemic (Browning et al., 2021; Oducado et al., 2021; Rogowska et al., 2020; Tee et al., 2020). On the other hand, chronic conditions were associated with lower health-related quality of life (Tran et al., 2020). Our finding suggests that the general health status of students should be given focus at this time of health catastrophe. Likewise, students should be made aware of their current health status and the possible presence of comorbidities that might increase their risk of severe COVID-19 illness (Guillasper et al., 2021).

Meanwhile, this study also found that younger students have poor mental wellbeing and life satisfaction. Thus, younger age groups and students are particularly at risk of experiencing the pandemic's negative mental and psychological impact (Browning et al., 2021; Cleofas \& Rocha, 2021; Tee et al., 2020; Wang et al., 2021b). Perhaps, younger students are more likely to be worried about their future education (Aristovnik et al., 2020; Browning et al., 2021) but are less likely to use positive coping strategies, making them more vulnerable to psychopathologies or negative mental states during the pandemic (Labrague et al., 2021). Therefore, it is crucial to proactively reach out to students who are likely to experience mental health issues and provide them with accessible mental health care (Lee et al., 2021).

On the brighter side, this study found that a little over half of the students are highly satisfied with their life. On the other hand, studies elsewhere noted a decline in life satisfaction related to the COVID-19 pandemic (Duong, 2021; Pretorius \& Padmanabhanunni, 2021; Von Soest et al., 2020). The varying times the studies were 
conducted, the use of different tools to assess a similar construct, and the different scoring and interpretation procedures of various scholars may have influenced the results. Moreover, while mental well-being, selfreported health, and age can explain $40.7 \%$ of the variances of the satisfaction with life, there may be other factors contributing to college students' life satisfaction. Other factors found in the literature that are linked with life satisfaction are satisfaction with family life (Schnettler et al., 2017), stress and ego-resilience (Kim \& Koh, 2016), and academic performance, and physical activities (Slavinski et al., 2021), among others. Future researchers may consider these variables when studying life satisfaction in the current or similar context.

Finally, we also demonstrated in this study that students' mental well-being predicts their satisfaction with life. Our finding is consistent with the results of studies conducted elsewhere, like in Canada (Lombardo et al., 2018) and China (Bieda et al., 2019). Therefore, the promotion of mental well-being is necessary to enhance life satisfaction among college students.

Nonetheless, our study has the following limitations. First, it must be noted that our outcome measures (subjective mental well-being and life satisfaction) are dependent on students' self-report and not meant to diagnose any psychopathology. Functional neuroimaging and structured clinical interviews are the gold standards for establishing the psychiatric diagnosis (Husain et al., 2020, Ho et al., 2020b). Moreover, our study is limited to its cross-sectional nature and our single-site sample, which decreases its generalizability and ability to establish causality among variables. There may be other factors that could contribute to students' mental outcomes not included in the study. Future researchers may investigate if vaccination could improve mental health and may follow the design of studies found in the literature (e.g., Chew et al., 2021). Nevertheless, our findings enrich the literature on the mental and psychological outcomes of the pandemic among college students. We provide up-to-date evidence on students' mental well-being and life satisfaction after over a year of the inception of the COVID-19 crisis.

\section{CONCLUSION}

This study highlights that the mental health aspect of college students should be given priority during the pandemic. Our study suggests that the rather long-term presence of the COVID-19 pandemic has likely affected college students' mental well-being and psychological health resulting in a looming mental health crisis. Also, students' mental well-being is a valuable resource that contributes to their life satisfaction. Moreover, this research found that younger students with lower general self-reported health status tend to have poor subjective mental well-being and life satisfaction. Therefore, attention should be given to the cohort of students at risk of mental health issues and are likely to report lower mental well-being. Some students may need professional help dealing with the pandemic, 
and mental health care should be made accessible and available to them. Preventive strategies and mental health promotion interventions may be initiated to respond to the growing mental health needs of the students during this pandemic and as the long-term effects of the pandemic continue to unfold.

\section{ACKNOWLEDGEMENT}

The authors would like to thank all students who invested their time to partake in this study.

\section{REFERENCES}

Aristovnik, A., Keržič, D., Ravšelj, D., Tomaževič, N., \& Umek, L. (2020). Impacts of the COVID-19 pandemic on life of higher education students: A global perspective. Sustainability, 12(20), Article 8438. https://doi.org/10.3390/su12208438

Bieda, A., Hirschfeld, G., Schönfeld, P., Brailovskaia, J., Lin, M., \& Margraf, J. (2019). Happiness, life satisfaction and positive mental health: Investigating reciprocal effects over four years in a Chinese student sample. Journal of Research in Personality, 78, 198-209. https:// doi.org/10.1016/j.jrp.2018.11.012

Brådvik, L. (2018). Suicide risk and mental disorders. International Journal of Environmental Research and Public Health, 15(9), Article 2028. https:// doi.org/10.3390/ijerph15092028

Browning, M. H., Larson, L. R., Sharaievska, I., Rigolon, A., McAnirlin, O., Mullenbach, L., Cloutier, S., Vu, T. M., Thomsen, J., Reigner, N., Metcalf, E. C., D’Antonio, A., Helbich, M., Bratman, G. N., \& Alvarez, H. O. (2021). Psychological impacts from COVID-19 among university students: Risk factors across seven states in the United States. PloS One, 16(1),
Article e0245327. https://doi.org/10.1371/ journal.pone. 0245327

Burns, D., Dagnall, N., \& Holt, M. (2020). Assessing the impact of the COVID-19 pandemic on student wellbeing at universities in the United Kingdom: A conceptual analysis. Frontiers in Education, 5, Article 582882. https://doi. org/10.3389/feduc. 2020.582882

Ceri, V., \& Cicek, I. (2021). Psychological wellbeing, depression and stress during COVID-19 pandemic in Turkey: A comparative study of healthcare professionals and non-healthcare professionals. Psychology, Health \& Medicine, 26(1), 85-97. https://doi.org/10.1080/13548506 .2020 .1859566

Chew, N. W., Cheong, C., Kong, G., Phua, K., Ngiam, J. N., Tan, B. Y., Wang, B., Hao, F., Tan, W., Han, X., Tran, B. X., Hoang, M. T., Pham, H. Q., Vu, G. T., Chen, Y., Danuaji, R., Kolkumar, R. N., Meenakshi, P. V., Talati, K., ... Sharma, V. K. (2021). An Asia-Pacific study on healthcare workers' perceptions of, and willingness to receive, the COVID-19 vaccination. International Journal of Infectious Diseases, 106, 52-60. https://doi.org/10.1016/j. ijid.2021.03.069

Cleofas, J. V. (2020). Life interruptions, learnings and hopes among Filipino college students during COVID-19 pandemic. Journal of Loss and Trauma, 1-9. https://doi.org/10.1080/1532502 4.2020 .1846443

Cleofas, J. V., \& Oducado, R. M. F. (2021). COVID-19 death occurrences, pandemic fatigue and wellbeing. Journal of Loss and Trauma. https://doi. org/10.1080/15325024.2021.1971423

Cleofas, J. V., \& Rocha, I. C. N. (2021). Demographic, gadget and internet profiles as determinants of disease and consequence related COVID-19 anxiety among Filipino college students. Education and Information Technologies, 1-16. https://doi.org/10.1007/s10639-021-10529-9 
Cucinotta, D., \& Vanelli, M. (2020). WHO declares COVID-19 a pandemic. Acta Bio Medica: Atenei Parmensis, 91(1), 157-160. https://doi. org/10.23750/abm.v91i1.9397

Diener, E., Emmons, R. A., Larsen, R. J., \& Griffin, S. (1985). The satisfaction with life scale. Journal of Personality Assessment, 49(1), 71-75. https:// doi.org/10.1207/s15327752jpa4901_13

Dodson, K. (2020). COVID-19 is fueling a mental health crisis for the world's youth. United Nations Foundation. https://unfoundation.org/ blog/post/covid-19-is-fueling-a-mental-healthcrisis-for-the-worlds-youth/

Duong, C. D. (2021). The impact of fear and anxiety of Covid-19 on life satisfaction: Psychological distress and sleep disturbance as mediators. Personality and Individual Differences, 178, Article 110869. https://doi.org/10.1016/j. paid.2021.110869

Elbogen, E. B., Lanier, M., Blakey, S. M., Wagner, H. R., \& Tsai, J. (2021). Suicidal ideation and thoughts of self-harm during the COVID-19 pandemic: The role of COVID-19-related stress, social isolation, and financial strain. Depression and Anxiety, 38(7), 739-748. https:// doi.org/10.1002/da.23162

Guillasper, J. N., Oducado, R. M. F., \& Soriano, G. P. (2021). Protective role of resilience on COVID-19 impact on the quality of life of nursing students in the Philippines. Belitung Nursing Journal, 7(1), 43-49. https://doi. org/10.33546/bnj.1297

Haddock, C. K., Poston, W. S., Pyle, S. A., Klesges, R. C., Vander Weg, M. W., Peterson, A., \& Debon, M. (2006). The validity of self-rated health as a measure of health status among young military personnel: Evidence from a cross-sectional survey. Health and Quality of Life Outcomes, 4(1), 57. https://doi.org/10.1186/1477-7525-4-57

Hamaideh, S. H., Al-Modallal, H., Tanash, M. A., \& Hamdan-Mansour, A. (2021). Depression, anxiety and stress among undergraduate students during COVID-19 outbreak and "home-quarantine". Nursing Open. https://doi. org/10.1002/nop2.918

Hernández-Torrano, D., Ibrayeva, L., Sparks, J., Lim, N., Clementi, A., Almukhambetova, A., Nurtayev, Y., \& Muratkyzy, A. (2020). Mental health and well-being of university students: A bibliometric mapping of the literature. Frontiers in Psychology, 11, 1226. https://doi.org/10.3389/ fpsyg.2020.01226

Ho, C. S. H., Chee, C. Y. I., \& Ho, R. C. M. (2020a). Mental health strategies to combat the psychological impact of COVID-19 beyond paranoia and panic. Annals, Academy of Medicine, Singapore, 49(1), 1-3.

Ho, C. S. H., Lim, L. J., Lim, A. Q., Chan, N. H., Tan, R. S., Lee, S. H., \& Ho, R. (2020b). Diagnostic and predictive applications of functional nearinfrared spectroscopy for major depressive disorder: A systematic review. Frontiers in Psychiatry, 11, 378. https://doi.org/10.3389/ fpsyt.2020.00378

Husain, S. F., Yu, R., Tang, T. B., Tam, W. W., Tran, B., Quek, T. T., Quek, T. T., Hwang, S. H., Chang, C. W., Ho, C. S., \& Ho, R. C. (2020). Validating a functional near-infrared spectroscopy diagnostic paradigm for major depressive disorder. Scientific Reports, 10, 9740. https://doi.org/10.1038/s41598-020-66784-2

Joseph, A. (2021). As the COVID-19 crisis ebbs in the U.S., experts brace for some to experience psychological fallout. STAT News. https:/www. statnews.com/2021/05/07/as-the-covid-19crisis-ebbs-in-the-u-s-experts-brace-for-a-longterm-impact-on-mental-health/

Kecojevic, A., Basch, C. H., Sullivan, M., \& Davi, N. K. (2020). The impact of the COVID-19 epidemic on mental health of undergraduate students in New Jersey, cross-sectional study. PloS One, 15(9), Article e0239696. https://doi. org/10.1371/journal.pone.0239696 
Kim, Y. H., \& Koh, T. S. (2016). Factors affecting on life satisfaction of university students: Focusing on the moderating effects of ego-resilience. Journal of the Korea Academia-Industrial Cooperation Society, 17(10), 481-489. https:// doi.org/10.5762/KAIS.2016.17.10.481

Labrague, L., \& Ballad, C. A. (2020). Lockdown fatigue among college students during the covid-19 pandemic: Predictive role of personal resilience, coping behaviours, and health. Perspectives in Psychiatric Care. https://doi. org/10.1111/ppc.12765

Labrague, L. J., De los Santos, J. A. A., \& Falguera, C. C. (2021). Social and emotional loneliness among college students during the COVID-19 pandemic: The predictive role of coping behaviors, social support, and personal resilience. Perspectives in Psychiatric Care. https://doi.org/10.1111/ ppc. 12721

Le, H. T., Lai, A. J. X., Sun, J., Hoang, M. T., Vu, L. G., Pham, H. Q., Nguyen, T. H., Tran, B. X., Latkin, C. A., Le, X. T. T., Nguyen, T. T., Pham, Q. T., Ta, N. T. K., Nguyen, Q. T., Ho, R. C. M., \& Ho, C. S. H. (2020). Anxiety and depression among people under the nationwide partial lockdown in Vietnam. Frontiers in Public Health, 8, 656. https://doi.org/10.3389/ fpubh.2020.589359

Lee, J., Jeong, H. J., \& Kim, S. (2021). Stress, anxiety, and depression among undergraduate students during the COVID-19 pandemic and their use of mental health services. Innovative Higher Education, 1-20. https://doi.org/10.1007/s10755021-09552-y

Lim, G. Y., Tam, W. W., Lu, Y., Ho, C. S., Zhang, M. W., \& Ho, R. C. (2018). Prevalence of depression in the community from 30 countries between 1994 and 2014. Scientific Reports, 8, 2861. https://doi.org/10.1038/s41598-018-21243-x

Lim, K. S., Wong, C. H., McIntyre, R. S., Wang, J., Zhang, Z., Tran, B. X., Tan, W., Ho, C. S., \&
Ho, R. C. (2019). Global lifetime and 12-month prevalence of suicidal behavior, deliberate selfharm and non-suicidal self-injury in children and adolescents between 1989 and 2018: A metaanalysis. International Journal of Environmental Research and Public Health, 16(22), 4581. https://doi.org/10.3390/ijerph16224581

Lombardo, P., Jones, W., Wang, L., Shen, X., \& Goldner, E. M. (2018). The fundamental association between mental health and life satisfaction: Results from successive waves of a Canadian national survey. BMC Public Health, 18, 342. https://doi.org/10.1186/s12889-0185235-x

Malone, C., \& Wachholtz, A. (2018). The relationship of anxiety and depression to subjective wellbeing in a mainland Chinese sample. Journal of Religion and Health, 57(1), 266-278. https://doi. org/10.1007/s10943-017-0447-4

Mamun, M. A. (2021). Suicide and suicidal behaviors in the context of CoViD-19 pandemic in Bangladesh: A systematic review. Psychology Research and Behavior Management, 14, 695704. https://doi.org/10.2147/PRBM.S315760

NHS Health Scotland, University of Warwick, and University of Edinburgh. (2008). Short Warwick Edinburgh mental well-being scale (SWEMWBS). https://www.corc.uk.net/media/1245/swemwbs childreported.pdf

Oducado, R. M. F., \& Estoque, H. (2021). Online learning in nursing education during the covid-19 pandemic: Stress, satisfaction, and academic performance. Journal of Nursing Practice, 4(2), 143-153. https://doi.org/10.30994/jnp.v4i2.128

Oducado, R. M. F., Rabacal, J. S., Moralista, R. M., \& Tamdang, K. A. (2021). Perceived stress due COVID-19 pandemic among employed professional teachers. International Journal of Educational Research and Innovation, (15), 305316. https://doi.org/10.46661/ijeri.5284 
Pavot, W., \& Diener, E. (2013). The satisfaction with life scale (SWL). Measurement Instrument Database for the Social Science. https://www. midss.org/content/satisfaction-life-scale-swl

Philippine Department of Health. (2021). COVID-19 case tracker. https://doh.gov.ph/covid-19/casetracker

Pretorius, T., \& Padmanabhanunni, A. (2021). A looming mental health pandemic in the time of COVID-19? Role of fortitude in the interrelationship between loneliness, anxiety, and life satisfaction among young adults. South African Journal of Psychology, 51(2), 256-268. https://doi.org/10.1177/0081246321991030

Rabacal, J. S., Oducado, R. M. F., \& Tamdang, K. A. (2020). COVID-19 impact on the quality of life of teachers: A cross-sectional study. Asian Journal for Public Opinion Research, 8(4), 478492. https://doi.org/10.15206/ajpor.2020.8.4.478

Ren, Z., Xin, Y., Ge, J., Zhao, Z., Liu, D., Ho, R. C. M., \& Ho, C. S. H. (2021). Psychological impact of COVID-19 on college students after school reopening: A cross-sectional study based on machine learning. Frontiers in Psychology, 12, 1346. https://doi.org/10.3389/fpsyg.2021.641806

Repišti, S., Jovanović, N., Kuzman, M. R., Medved, S., Jerotić, S., Ribić, E., Majstorović, T., Simoska, S. M., Novotni, L., Milutinović, M., Stoilkovska, B. B., Radojičić, T., Ristić, I., Zebić, M., Pemovska, T., \& Russo, M. (2020). How to measure the impact of the COVID-19 pandemic on quality of life: COV19-QoL - the development, reliability and validity of a new scale. Global Psychiatry, 3(2), 1-10. https://doi. org/10.2478/gp-2020-0016

Rodríguez-Rey, R., Garrido-Hernansaiz, H., \& Collado, S. (2020). Psychological impact and associated factors during the initial stage of the coronavirus (COVID-19) pandemic among the general population in Spain. Frontiers in Psychology, 11, 1540. https://doi.org/10.3389/ fpsyg.2020.01540
Rogowska, A. M., Kuśnierz, C., \& Bokszczanin, A. (2020). Examining anxiety, life satisfaction, general health, stress and coping styles during COVID-19 pandemic in Polish sample of university students. Psychology Research and Behavior Management, 13, 797-811. https://doi. org/10.2147/PRBM.S266511

Schnettler, B., Miranda-Zapata, E., Grunert, K. G., Lobos, G., Denegri, M., Hueche, C., \& Poblete, H. (2017). Life satisfaction of university students in relation to family and food in a developing country. Frontiers in Psychology, 8, 1522. https://doi.org/10.3389/fpsyg.2017.01522

Simegn, W., Dagnew, B., Yeshaw, Y., Yitayih, S., Woldegerima, B., \& Dagne, H. (2021). Depression, anxiety, stress and their associated factors among Ethiopian university students during an early stage of COVID-19 pandemic: An online-based cross-sectional survey. PloS One, 16(5), Article e0251670. https://doi. org/10.1371/journal.pone.0251670

Slavinski, T., Bjelica, D., Pavlović, D., \& Vukmirović, V. (2021). Academic performance and physical activities as positive factors for life satisfaction among university students. Sustainability, 13(2), 497. https://doi.org/10.3390/su13020497

Soh, H. L., Ho, R. C., Ho, C. S., \& Tam, W. W. (2020). Efficacy of digital cognitive behavioural therapy for insomnia: A meta-analysis of randomised controlled trials. Sleep Medicine, 75, 315-325. https://doi.org/10.1016/j.sleep.2020.08.020

Stewart-Brown, S., Tennant, A., Tennant, R., Platt, S., Parkinson, J., \& Weich, S. (2009). Internal construct validity of the Warwick-Edinburgh mental well-being scale (WEMWBS): A Rasch analysis using data from the Scottish health education population survey. Health and Quality of Life Outcomes, 7(15). https://doi. org/10.1186/1477-7525-7-15

Superio, D. L., Anderson, K. L., Oducado, R. M. F., Luceño, M. T., Palcullo, V. E. V., \& Bendalian, M. V. T. (2021). The information-seeking behavior 
and levels of knowledge, precaution, and fear of college students in Iloilo, Philippines amidst the COVID-19 pandemic. International Journal of Disaster Risk Reduction, Article 102414. https:// doi.org/10.1016/j.ijdrr.2021.102414

Tee, M. L., Tee, C. A., Anlacan, J. P., Aligam, K. J. G., Reyes, P. W. C., Kuruchittham, V., \& Ho, R. C. (2020). Psychological impact of COVID-19 pandemic in the Philippines. Journal of Affective Disorders, 277, 379-391. https://doi. org/10.1016/j.jad.2020.08.043

Trabelsi, K., Ammar, A., Masmoudi, L., Boukhris, O., Chtourou, H., Bouaziz, B., Brach, M., Bentlage, E., How, D., Ahmed, M., Mueller, P., Mueller, N., Hsouna, H., Elghoul, Y., Romdhani, M., Hammouda, O., Paineiras-Domingos, L. L., Braakman-Jansen, A., Wrede, C., ... ECLBCOVID19 Consortium. (2021). Sleep quality and physical activity as predictors of mental wellbeing variance in older adults during COVID-19 lockdown: ECLB COVID-19 international online survey. International Journal of Environmental Research and Public Health, 18(8), Article 4329. https://doi.org/10.3390/ ijerph18084329

Tran, B. X., Nguyen, H. T., Le, H. T., Latkin, C. A., Pham, H. Q., Vu, L. G., Le, X. T. T., Nguyen, T. T., Pham, Q. T., Ta, N. T. K., Nguyen, Q. T., Ho, C. S. H., \& Ho, R. C. (2020). Impact of COVID-19 on economic well-being and quality of life of the Vietnamese during the national social distancing. Frontiers in Psychology, 11, Article 565153. https://doi.org/10.3389/ fpsyg.2020.565153

United Nations. (2020). COVID-19 and the need for action on mental health [Working paper]. https:// doi.org/10.18356/13fff923-en

Von Soest, T., Bakken, A., Pedersen, W., \& Sletten, M. A. (2020). Life satisfaction among adolescents before and during the COVID-19 pandemic. Tidsskrift for Den norske legeforening, 140(10). https://doi.org/10.4045/tidsskr.20.0437
Wang, C., Chudzicka-Czupała, A., Tee, M. L., Núñez, M. I. L., Tripp, C., Fardin, M. A., Habib, H. A., Tran, B. X., Adamus, K., Anlacan, J., Aparicio García, M. E., Grabowski, D., Hussain, S., Hoang, M. T., Hetnał, N., Le, X. T., Ma, W., Pham, H. Q., Reyes, P. W. C., ... Sears, S. F. (2021a). A chain mediation model on COVID-19 symptoms and mental health outcomes in Americans, Asians and Europeans. Scientific Reports, 11, 6481. https://doi.org/10.1038/ s41598-021-85943-7

Wang, C., Pan, R., Wan, X., Tan, Y., Xu, L., Ho, C. S., \& Ho, R. C. (2020a). Immediate psychological responses and associated factors during the initial stage of the 2019 coronavirus disease (COVID-19) epidemic among the general population in China. International Journal of Environmental Research and Public Health, 17(5), Article 1729. https://doi.org/10.3390/ ijerph17051729

Wang, C., Pan, R., Wan, X., Tan, Y., Xu, L., McIntyre, R. S., Choo, F. N., Tran, B., Ho, R., Sharma, V. K., \& Ho, C. (2020b). A longitudinal study on the mental health of general population during the COVID-19 epidemic in China. Brain, Behavior, and Immunity, 87, 40-48. https://oi. org/10.1016/j.bbi.2020.04.028

Wang, C., Tee, M., Roy, A. E., Fardin, M. A., Srichokchatchawan, W., Habib, H. A., Tran, B. X., Hussain, S., Hoang, M. T., Le, X. T., Ma, W., Pham, H. Q., Shirazi, M., Taneepanichskul, N., Tan, Y., Tee, C., Xu, L., Xu, Z., Vu, G. T., ... Kuruchittham, V. (2021b). The impact of COVID-19 pandemic on physical and mental health of Asians: A study of seven middle-income countries in Asia. PloS One, 16(2), Article e0246824. https://doi.org/10.1371/journal. pone. 0246824

Wąsowicz, G., Mizak, S., Krawiec, J., \& Białaszek, W. (2021). Mental health, well-Being, and psychological flexibility in the stressful times of the COVID-19 pandemic. Frontiers in 
Renante Adrogado Egcas, Ryan Michael Flores Oducado, Jerome Visperas Cleofas, Judith Solasco Rabacal and Samson Mahidlawon Lausa

Psychology, 12, Article 647975. https://doi. org/10.3389/fpsyg.2021.647975

World Health Organization. (2020). Adolescent mental health. https://www.who.int/news-room/factsheets/detail/adolescent-mental-health

World Health Organization. (2021). WHO Coronavirus (COVID-19) Dashboard. https://covid19.who. int/

Xiong, J., Lipsitz, O., Nasri, F., Lui, L. M., Gill, H., Phan, L., Chen-Li, D., Iacobucci, M., Ho, R., Majeed, A., \& McIntyre, R. S. (2020). Impact of COVID-19 pandemic on mental health in the general population: A systematic review. Journal of Affective Disorders, 277(1), 55-64. https://doi. org/10.1016/j.jad.2020.08.001

Zhang, M. W. B., \& Ho, R. C. M. (2017). Moodle: The cost effective solution for internet cognitive behavioral therapy (I-CBT) interventions. Technology and Health Care: Official Journal of the European Society for Engineering and Medicine, 25(1), 163-165. https://doi. org/10.3233/THC-161261 